\title{
Accuracy Comparison of Aerial Lidar, Mobile-Terrestrial Lidar, and UAV Photogrammetric Capture Data Elevations over Different Terrain Types
}

\author{
Mandar Khanal ${ }^{1, *}$, Mahamudul Hasan ${ }^{1}$, Nikolaus Sterbentz ${ }^{2}$, Ryen Johnson ${ }^{2}$ \\ and Jesse Weatherly ${ }^{3}$ \\ 1 Department of Civil Engineering, Boise State University, Boise, ID 83725, USA; \\ mahamudulhasan@u.boisestate.edu \\ 2 Idaho Transportation Department, District 5, Pocatello, ID 83204, USA; \\ Nikolaus.Sterbentz@itd.idaho.gov (N.S.); Ryen.Johnson@itd.idaho.gov (R.J.) \\ 3 David Evans and Associates, Inc., Spokane, WA 99201, USA; Jesse.Weatherly@deainc.com \\ * Correspondence: mkhanal@boisestate.edu; Tel.: +1-208-426-1430
}

Received: 6 July 2020; Accepted: 28 July 2020; Published: 31 July 2020

check for updates

\begin{abstract}
Lidar and other remotely sensed data such as UAV photogrammetric data capture are being collected and utilized for roadway design on an increasing basis. These methods are desirable over conventional survey due to their efficiency and cost-effectiveness over large areas. A high degree of relative accuracy is achievable through the establishment of survey control. In this case study, elevations (z-values) derived from mobile-terrestrial lidar, aerial lidar, and UAV photogrammetric capture collected with survey control were statistically compared to conventionally surveyed elevations. A cost comparison of the methods is also included. Each set of z-values corresponds to a discrete horizontal point originally part of the conventional survey, collected as cross-sections. These cross-sections were surveyed at three approximate tenth-mile sample locations along US-30 near Georgetown, Idaho. The cross-sections were collected as elevational accuracy verification, and each sample location was selected as an area where the mobile-terrestrial lidar in particular was expected to have more difficulty achieving accuracy off the road surface. Processing and analysis were performed in Esri ArcMap 10.6, and all data were obtained from the Idaho Transportation Department, District 5. Overall, the aerial lidar elevations were found to be closest to conventionally surveyed elevations; on road surface and level terrain, mobile-terrestrial and UAV photogrammetric capture elevations were closer to the conventionally measured elevations.
\end{abstract}

Keywords: lidar; unmanned aerial vehicles; road design; UAV photogrammetric data capture; terrain models

\section{Introduction}

Designing new or existing transportation facilities requires accurate surface terrain information [1]. Conventional survey methods for acquiring accurate terrain surfaces include Real Time Kinematic Global Positioning System (RTK-GPS), Electronic Distance Measurement (Total Station), and photogrammetry. Generally, RTK-GPS and Total Station procedures are time-consuming and costly due to the necessity of workers and equipment needing to physically move across the terrain of an area to achieve satisfactory coverage. Certain operational constraints such as dense vegetation cover must also be considered, and in the case of conventional survey on existing road design projects, vehicular traffic is a further safety consideration. While large-area terrain information can be collected through these methods, the time and effort needed is significant. 
Photogrammetry circumvents some of the limitations of RTK-GPS and Total Station survey but introduces other issues. Imagery used for photogrammetric data must typically be gathered in highly specific conditions, usually when foliage is in a bare, leaf-off state but before the ground is covered by snow and ice [1]. Photogrammetry also requires a particular sun angle with no cloud cover present. Once photogrammetric imagery is collected, processing the data and determining elevation is often time-consuming.

Lidar data is an alternative to these methods and may be used for road design if their accuracy is within an acceptable range. UAV photogrammetric capture data is another option, especially for smaller areas. Even though UAV photogrammetric capture is based on photogrammetry, it is a much lower cost alternative relative to aerial photography and can be convenient for smaller projects. In fact, UAV photogrammetry may produce better results, when properly controlled with appropriate ground control, than traditional manned-aircraft photogrammetry because it produces positions from images that are so much closer to the ground, so resolution can be much better, especially if high-end UAV sensors are used. The speed an airplane has to maintain to keep it in the air makes it impossible to get clear images from $400^{\prime}$ off the ground-A typical ceiling for small UAVs - so pixels, even of high-end wide-format cameras costing millions of dollars, refer to larger areas of land than in many small UAV models. Typical manned flight imagery provides a pixel resolution of $7.6 \mathrm{~cm}$ for highways; the UAV pixel resolution in this study was $1.6 \mathrm{~cm}$.

To assess the suitability of these alternative methods for road design applications, it is necessary to understand accuracy standards recommended for such work. According to the Idaho Transportation Department's (ITD) 2018 Standard Specifications for Highway Construction, original ground confidence point vertical tolerance values are as shown in Table 1 [2]:

Table 1. Idaho Transportation Department Highway Construction Specifications.

\begin{tabular}{cccc}
\hline Type & Surface Represented & Feet & Centimeters \\
\hline Surfaced & Paved or Concrete Surface & \pm 0.10 & \pm 3.048 \\
Graded & Machine Graded and Compacted Surface & \pm 0.30 & \pm 9.144 \\
Natural & Irregular Natural Ground & \pm 0.60 & \pm 18.288 \\
Rugged & Extremely Rugged \& Rock Surface & \pm 1.50 & \pm 45.72 \\
\hline
\end{tabular}

An additional measure to check the accuracy of the collected Lidar data is to compare the Root Mean Square Error (RMSE) for the difference between the remote source data and the conventional survey data with the standard accuracy limit stipulated by the Idaho Lidar Consortium (ILC). According to ILC, any RMSE less than $12.5 \mathrm{~cm}$ is within their accuracy standard [3]. ILC defines three types of vertical accuracy: Fundamental, Supplemental, and Consolidated. The accuracy threshold specified above is for Fundamental Vertical Accuracy (FVA), which is applicable for open terrain. In other words, FVA is applicable when we can assume that the sensor is able to detect the ground surface.

By supplementing these data with survey control methods, a high degree of accuracy can be achieved. Lidar (light detection and ranging) is an active remote sensing technique that uses laser light to measure distance by illuminating an object and measuring the reflected light with a sensor. Common acquisition methods include mounting a lidar device on an aircraft or ground-based vehicle and moving while the device continuously collects point data. The result is a "point cloud" dataset of lidar point locations, from which elevation models can be created. Compared to the previously described conventional survey methods, lidar is generally considered to offer safer data collection, cost effectiveness, and a high level of detail [4].

Another remote sensing technique is the use of an unmanned aerial vehicle (UAV) to acquire photogrammetric capture data through the collection of a large volume of photographs. This method utilizes a digital structure from motion process with scale invariant feature transform tools. Essentially, this uses the parallax differences between photographs to generate a three-dimensional model of its target. A digital surface terrain model can be generated using this output, as well as a 
point cloud file or files resembling a lidar point cloud dataset. Although this method has some of the same issues as "traditional" photogrammetry, it is generally considered a less-expensive alternative to both conventional survey and lidar.

The accuracy of lidar data has been compared to conventional survey points in other research. For example, Pourali et al. utilize this general technique to determine vertical accuracy for a test lidar dataset, noting its suitability for purposes requiring an accuracy of up to $0.5 \mathrm{~m}$ for a large area of aerial lidar in Victoria, Australia [5]. Hodgson and Bresnahan used a similar approach to test aerial lidar accuracy as part of a large-scale mapping effort for Richland County, South Carolina [6]. Lidar accuracy depends on the entire workflow starting from data acquisition through generating the final terrain model. Researchers have noted that high quality digital terrain models (DTMs) can be generated with suitable processing techniques, which take into account a variety of factors including the multiple returns lidar typically produces [7]. For example, classifying lidar data allows for differentiating between the ground, foliage, buildings, and water surface in the point cloud. Besides roadway design, lidar is routinely used in a variety of applications including forest inventory and assessment $[8,9]$, hydrologic channeling [10], and carbon sequestration [11].

Lidar used for roadway design is usually collected expressly for this purpose, and studies [5,6] have shown a root mean square error (RMSE) of $0.18-0.50 \mathrm{~m}$ for vertical accuracy. One of the earlier studies has reported RMSEs between $0.06-0.10 \mathrm{~m}$ over a road right-of-way [12]. But this low level of RMSE was achieved after removing systematic biases that ranged from about 20 to $-10 \mathrm{~cm}$. In the years since these studies, improvement in lidar accuracy is reflected in standards such as the latest USGS Lidar Base Specification. This publication lists a relative vertical accuracy of less than or equal to $0.06 \mathrm{~m}$ for smooth surface repeatability and $0.08 \mathrm{~m}$ for swath overlap difference [13]. The accuracy of lidar-derived digital elevation model (DEM) rasters has been researched over a variety of vegetation and terrain types [14]. One study indicates that increasing terrain slope leads to lower lidar canopy height estimates because slope has effect on DEM accuracy [15]. As part of this study, the effects of both slope and terrain type on lidar vertical accuracy will be examined.

The Australian study cited above [5] has reported vertical accuracy from aerial lidar of $50 \mathrm{~cm}$. Their definition of vertical accuracy was a $95 \%$ confidence interval assuming a normal distribution of RMSEs. In other words, the vertical accuracy reported was 1.95 times the mean RMSE. Using this definition, the vertical accuracy for our study, as will be seen later, will calculate to $17.7 \mathrm{~cm}$, which is much lower than the $50 \mathrm{~cm}$ reported in the Australian study. This difference is remarkable since the procedure to estimate RMSE in the Australian study was very elaborate compared to the method used in our study. All lidar points within $1 \mathrm{~m}$ of a Ground Control Point (GCP) were identified in the Australian study. The points were ranked in terms of the distance from the GCP. RMSEs for the set of points closest to the GCPs were computed, followed by the points second closest to the GCP, and so on. The RMSEs were then averaged. This elaborate procedure was adopted supposedly to prevent interpolation errors which are thought to be introduced when deriving elevations from a DEM generated from the lidar point elevations. Our study used such a DEM generated by ArcGIS. Yet the accuracy obtained in this study was higher than the one reported by Pourali et al. [5].

Another study that has examined accuracy of airborne lidar as reported earlier is by Hodgson and Bresnahan [6]. In Hodgson and Bresnahan study, elevations of selected lidar points were measured using conventional survey methods and compared with the lidar-determined elevations. This was done to control for errors that could potentially be introduced when interpolating from a DEM. This is in contrast to what was done in our study, where ground points were first established and their elevations measured. These elevations were then compared with the elevations estimated for these points using a DEM that was created from lidar points. The RMSE obtained by Hodgson and Bresnahan for pavement surface was $18.9 \mathrm{~cm}$, which is much higher than the value reported in our research for pavement surface as will be shown later in this paper. In fact, the overall RMSEs obtained in our research are lower than $18.9 \mathrm{~cm}$. This difference in findings in the two studies cannot be explained easily. Perhaps this is due to the improvement in the technologies of data collection and processing 
between the time the data used by Hodgson and Bresnahan were collected (October 2000) and the time when the data used in our study was collected (April-October 2016).

The civil engineering application addressed by this study is highway design. One study that measured elevations along a road corridor, as mentioned previously, was performed by Shrestha et al. [12]. Shrestha et al. state that the RMSE in their study "was approximately 6 to $10 \mathrm{~cm}$ over the entire right-of-way". This is a remarkable achievement, which is especially noteworthy because the data for their study was collected in November of 1997. None of the other more recent studies have reported accuracy levels of this order. It should be noted, however, that Shrestha et al. state that systematic biases that ranged from $20 \mathrm{~cm}$ to $-10 \mathrm{~cm}$ were removed from their data during calibration. The aerial lidar data used in our study was provided by Aero Graphics and we have no knowledge of their data processing efforts prior to submitting the data to ITD.

Review of literature on this topic has revealed that use of remote sources of data in highway design is sparse. And the studies that have explored this topic have reported widely varying accuracy levels. The accuracy levels reported have also been found not to be commensurate with the complexity of analytic methods used in the processing of the data. So, the main motivation of our study was to conduct and present a simple side-by-side comparison of remote data collection systems commonly available to highway design staff in state departments of transportation and engineering firms that provide design services to highway agencies. Analytical methods and software used in this study are similar to those readily available to agency staff. We hope that the findings from our study will encourage highway agencies to make more use of this readily available technology in some aspects of highway design.

\section{Study Objectives}

The following objectives were considered for this study:

1. Compare the vertical accuracy of the three test case datasets to traditional survey elevation ground points,

2. statistically determine whether the elevation differences between the test datasets are potentially acceptable for use in roadway design, and

3. perform a cost analysis of the different data collection methods.

\section{Materials and Methods}

\subsection{Study Area}

The study area, shown in Figure 1, consists of three approximate tenth-mile segments of US-30 in southeastern Idaho near Georgetown, corresponding roughly to mileposts 414, 419, and 422, respectively. Conventional survey cross-section points including elevation were collected for the Idaho Transportation Department (ITD) by Dioptra Geomatics on these segments to verify the accuracy of the mobile-terrestrial lidar featured in this study. Each of these areas was specifically chosen as an area that the mobile-terrestrial lidar may have difficulty with accuracy off the road surface. In this study, the verification purpose of the conventional survey has been expanded to the aerial lidar and UAV photogrammetric capture data covering the same general areas. All four datasets (aerial lidar, mobile-terrestrial lidar, UAV photogrammetric capture, and traditional survey cross-section points) were obtained from ITD. 

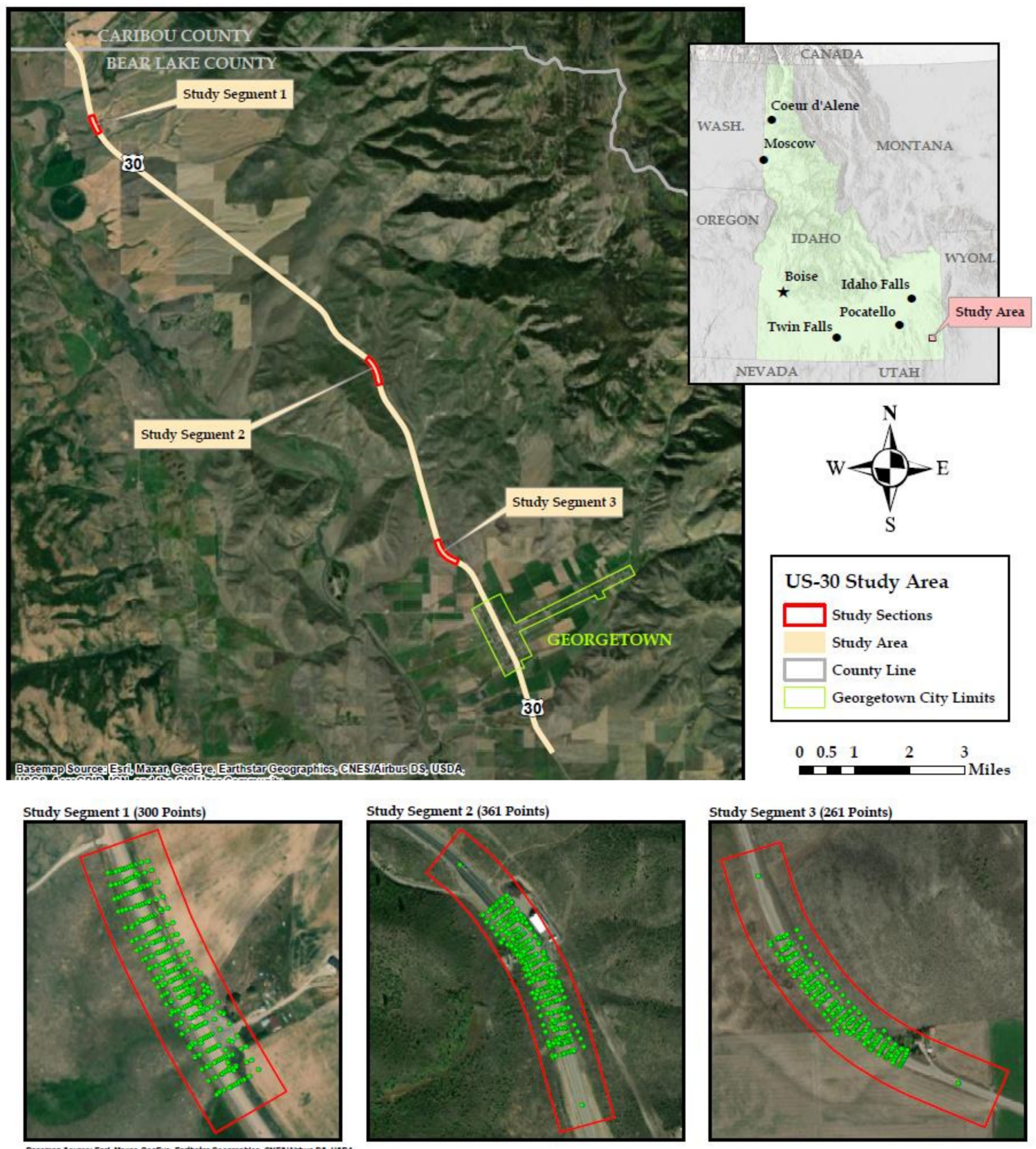

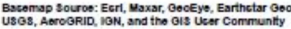

Figure 1. Google Earth image of the study area.

\subsection{Data Collection}

\subsubsection{Aerial Lidar}

The aerial lidar data used in this study was collected between April 7 and October 12, 2016 by Aero-Graphics, as part of an ITD District 5 district-wide aerial lidar and imagery collection project. Aero-Graphics certified the accuracy of these lidar data at "planning grade." In order to achieve a greater degree of horizontal accuracy, survey control targets were strategically placed along collected routes districtwide [16]. All data were collected using a custom districtwide coordinate projection, based on NAD 1983 Idaho State Plane East, intended to maintain regional measurement distances without needing to scale the data. The vertical datum used was NAVD88 (U.S. Feet). 
Collection was performed with an Optech ALTM Orion H300 sensor and an Optech CS-10000 aerial camera system, at an average $1006 \mathrm{~m}$ altitude. The lidar sensor and the camera were paired in a customized mount to improve accuracy and minimize error between datasets [16]. Aero-Graphics reported a 30\% overlap in the lidar data, yielding 9.6 points per square meter across the project. The pulse rate frequency used for the collection was $225 \mathrm{kHz}$ with scan frequency of $68.7 \mathrm{~Hz}$, and the scan angle was $+/-14.5^{\circ}$ from the nadir position (full scan angle $29^{\circ}$ ). The Orion $\mathrm{H} 300$ was equipped with a GPS/IMU unit, recording the XYZ position and roll, pitch, and yaw attitude of the plane throughout the flight. This allowed for the correction of lidar returns that may have been thrown off by the plane's motion during flight [16].

The vendor has provided vertical accuracy results for non-vegetated areas, which they define as open terrain (bare soil, sand, rocks, and short grass) as well as urban terrain (asphalt and concrete surfaces). They claim that they achieved an RMSE value of about $3.14 \mathrm{~cm}$ in their sample of 545 points.

\subsubsection{Mobile-Terrestrial Lidar}

The mobile-terrestrial lidar data was collected on November 15, 2016 by R.E.Y. Engineers, Inc. The collection device, mounted to a ground-based vehicle, was a RIEGL VMX-250 mobile scanning system, consisting of two RIEGL VQ-250 line scanners, two RIEGL CS6 5 MPx Cameras, $80^{\circ} \times 65^{\circ}$ FOV, an Applanix POS LV V5 Model 510 position and orientation system (IMU), a Trimble BD960 GNSS receiver, a Trimble Zephyr Model 2 GNSS Antenna, an Applanix Distance Measurement Indicator (DMI), and a RIEGL Control Unit (CU). For project control, Dioptra Geomatics set 110 control targets using RTK GPS, with the Utah Reference Network "TURN" solution to improve accuracy on most of these targets [17]. These lidar data were collected as part of ITD project A019(382), from the Caribou County line to Nounan Road on US-30 in Bear Lake County. As a result, the data were collected using a custom coordinate system, based on NAD 1983 Idaho State Plane East, specific to the project. It should be noted that this coordinate system is different than the districtwide coordinate system used for the Aero-Graphics aerial lidar.

The collection vehicle with the VMX-250 scanning system was driven two times in each direction for data quality purposes, at an average speed of $56 \mathrm{~km}$ per hour, varying between 48 and $64 \mathrm{~km}$ per hour. Each scanner was set for a measurement rate of $300 \mathrm{kHz}(600 \mathrm{kHz}$ combined). For each pass at this speed, R.E.Y. reported a point density on the road surface of approximately 340 points $/ \mathrm{m}^{2}$ at $6 \mathrm{~m}$ away from the sensors, to over 2000 points $/ \mathrm{m}^{2}$ along the trajectory line from the sensors as the data were collected [17]. Unlike the aerial lidar data, the mobile-terrestrial lidar data did not have classifications assigned. Ground classification were determined for this study using the Classify LAS Ground tool in Esri ArcMap.

The vendor has provided accuracy reports that compares surveyed scan targets to the finished point cloud data. The RMSE of error for sampled points of size 110 has been stated to be $0.732 \mathrm{~cm}$ for area comprising of pavement and edge of pavement. For "ground points", which presumably are points not on the pavement or edge of pavement, the RMSE of error was reported as $4.3 \mathrm{~cm}$ [17].

\subsubsection{UAV Photogrammetric Data Capture}

The photogrammetric-engineered dataset was collected October 11, 2018 by ITD District 5 with a DJI Phantom 4 UAV with a 12.4 megapixel RGB sensor, calibrated for photogrammetric work. Calibration included a manual application to calibrate for lighting. While a mechanical shutter may have improved accuracy, it is worth noting that this model was not equipped with a mechanical shutter.

The device was flown at an average elevation of $46 \mathrm{~m}$ above ground level using "terrain awareness" to follow features and create waypoints on the terrain based on a NASA/USGS DEM from Mapbox. The UAV had a relative accuracy GPS/GLONASS system on board and was flown with an iOS mobile command and control application called Map Pilot. Two flights on each section were conducted on either side of the road with 75\% front and side overlap and a solar elevation angle at nadir (solar noon) position for the particular date, derived from Spring/Fall NASA values. Approximately 330 aerial 
images were taken per road section at 3-s intervals. The image metadata Z-values (WGS84 EGM 96 Geoid) were manually adjusted in Microsoft Excel to correct the heights, and then processed in a key point matching process in Pix4D.

Nine aerial targets were set at each site to be used as ground control points, the coordinates of which were determined with a survey-grade RTK-GPS system using the same coordinate system and control point values as the on-the-ground survey data collection. The UAV-collected data was processed in Pix4D (including matching, extraction, densification, meshing, and scaling) utilizing Structure from Motion (SfM) and Scale Invariant Feature Transform (SIFT) tools to acquire a single image composed of the collected images. Using this composite, the program then produced 3D meshes and point clouds for each road section.

These produced data have a ground sampling distance of $1.5 \mathrm{~cm} /$ pixel. Pix $4 \mathrm{D}$ calculated a root mean square error of $17.1 \mathrm{~cm}$ for the data at the milepost 414 road section, $1.9 \mathrm{~cm}$ at the milepost 419 section, and $15.8 \mathrm{~cm}$ at the milepost 422 section, representing the difference between the initial and computed positions of the ground control points. Unsupervised point cloud classification was then performed in Pix4D on the point cloud to filter out points besides the "road" and "ground" points to create a digital terrain model (DTM). A georeferenced DTM LAS point cloud file was then produced and used for the analysis process, exported to unmodified NAD 1983 State Plane Idaho East. No supplemental boundary work was performed on the outer edges of the imagery. It should be noted that the Pix4D unsupervised classification process was limited in its capability to classify the data; a second automated classification of ground returns only was performed using the Classify LAS Ground tool in Esri ArcMap.

\subsubsection{Verification Survey}

The conventional survey data used in this study to compare the elevational accuracies of the three remote data types was collected by Dioptra Geomatics between April and May 2017 using a Total Station. QA/QC on these data included the standard survey practice of verifying, after data collection, that the backsight re-observation is within tolerance to the original observation. These cross-section points were collected for the purpose of verifying the accuracy of the mobile-terrestrial lidar and were collected using the same project-specific coordinate system. These verification surveys were used by R.E.Y. to examine the accuracy of the mobile-terrestrial lidar on pavement, at the edge of the pavement, and off-pavement ground using TopoDOT [17].

\subsection{Analysis}

For the analysis in this study, Esri ArcMap was specifically chosen, rather than survey or CADD software, due to its observational and analytical capabilities. The three test case datasets were provided by ITD as .las files and the conventional survey cross-section points were provided as an Esri Shapefile. The conventional survey points included codes indicating whether their location was on or off the road surface. Esri ArcMap software was used for viewing and working with the lidar data, including deriving bare-earth DEM rasters and preparing the data for statistical analysis. Elevation Z-values for each discrete survey point were derived from the three DEM surfaces to be compared to the conventional survey elevations for each point. The study road sections were subdivided into three categories to evaluate the effect of slope: level, moderate, and steep.

According to the AASHTO "Policy on Geometric Design of Highways and Streets" (commonly referred to as the "Green Book"), terrain with a slope between $0-2 \%$ is considered level, $2-5 \%$ is considered moderate, and slopes greater than 5\% are considered steep [18]. For the purposes of determining areas of level, moderate, and steep terrain for this analysis, degrees were used instead of percentage slope. Slope values less than $1^{\circ}$ were categorized as level, between $1^{\circ}$ and $5^{\circ}$ were categorized as moderate, and more than $5^{\circ}$ were categorized as steep. The location of each point was categorized by this slope index. Root mean square error (RMSE) was calculated for all elevation differences between the conventional survey points and their corresponding locations on the test data 
DEM surfaces. These RMSE values were further divided by study road section, location on or off the road, and slope value.

The las files were added to a new ArcMap document, and only ground return was selected to produce DEM surfaces. Lidar data typically includes a large number of points for returns other than bare ground, so this is an important step, necessary to produce a model of the ground only. Figure 2 shows the properties of the aerial lidar LAS Dataset:

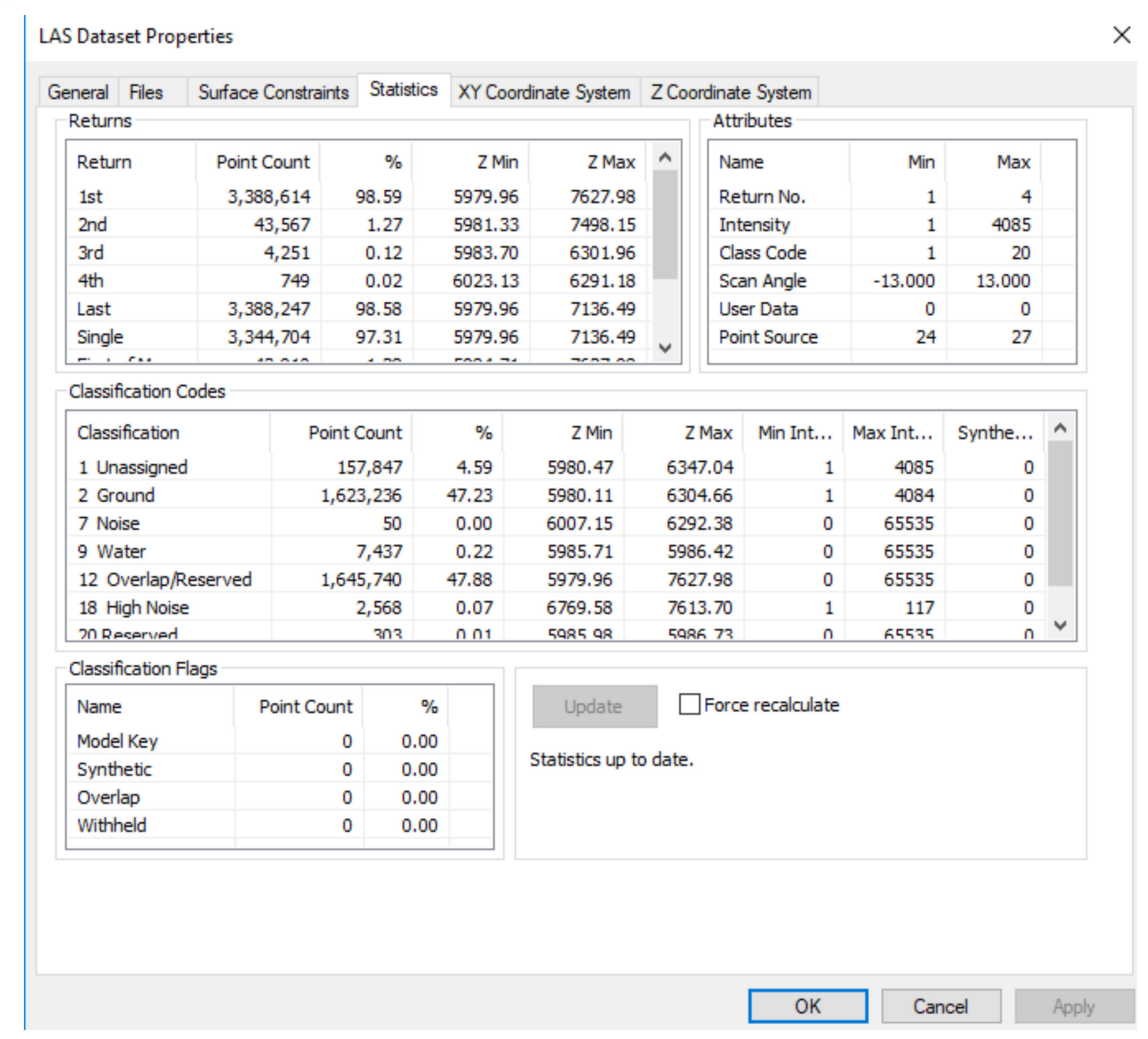

Figure 2. Classified aerial lidar data.

DEM surfaces were generated from the .las files, and these outputs were visually evaluated to ensure they covered the conventional survey points at each road section. Elevation data was then extracted from each DEM for each covered conventional survey point for aerial, mobile-terrestrial, and UAV data by using the Extract Values to Point (Spatial Analyst) tool. This process allowed for finding the elevations at the same horizontal points for the different data sources to statistically compare them. Figure 3 shows the survey points imported in ArcMap for a section of our study area.

Since the conventional survey data included each point's surveyed elevation with its horizontal $\mathrm{XY}$ coordinates, as well as code information indicating location and type, determining whether a specific point was a road-surface point or a non-road surface point was workable. This, along with the slope classification of each point, made it possible to analyze the survey points based on these classifications. RMSE was calculated for the differences between the surveyed elevation values and each DEM elevation value across all point locations. Further, RMSE was calculated for road-surface and non-road-surface points, and for each study road section independently. 


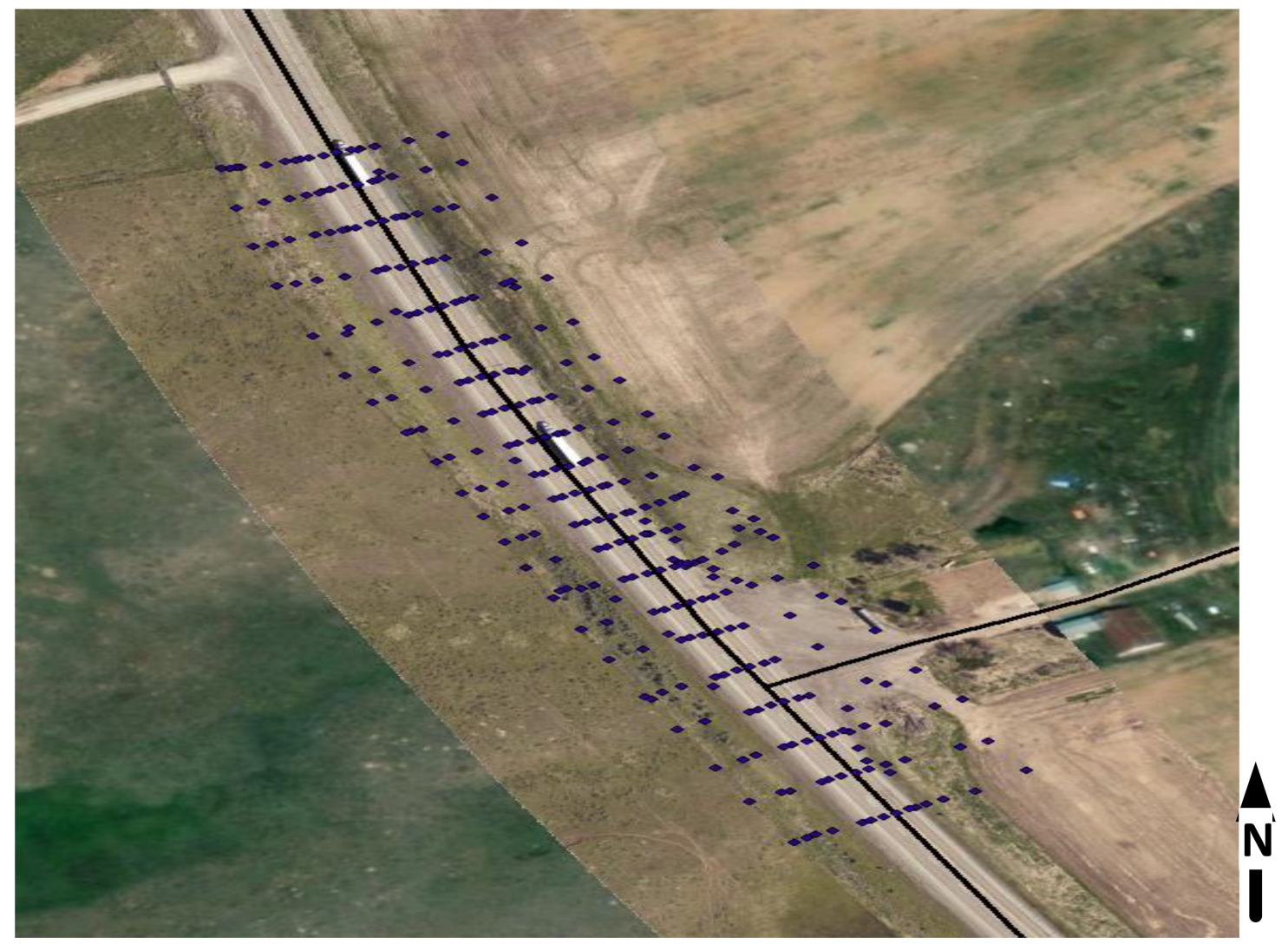

Figure 3. Survey points imported in ArcMap—Study Segment 1.

The Slope (Spatial Analyst) and Extract Values to Point (Spatial Analyst) tools in ArcMap were used to determine slope at each point to analyze the effect of slope on the test data vertical accuracy. The DEM raster files for each data type were input to determine slope, using "Degree" as the output measurement and the default method to calculate the slope. After calculating the slopes, they were classified into the three slope categories discussed previously: level, moderate, and steep. The process resulted in a new raster file for each corresponding input raster file, with slope values for the entire terrain covered area. Slope values were then extracted for aerial, mobile-terrestrial, and UAV data at each survey point.

\subsection{Statistical Analysis}

Two types of statistical analyses were performed to check the closeness of elevations obtained from the remote data sources and the conventially measured elevations for the points that were established during the verification survey. The first type was the estimation of confidence intervals around the mean difference between the elevations estimated from the remote source data and the elevations measured for the ground control points using conventional survey methods. The desired value for the mean differences is zero, which implies perfect correspondence between the elevations computed using the remote sources and the elevations established by the conventional survey. Such a perfect correspondence can never be expected, nevertheless, it is informative to see if a value of zero falls within some confidence intervals estimated around the calculated mean difference. The second type of anlysis involved estimating confidence intervals around the calculated RMSE and seeing if the ILC stipulated acceptable RMSE limit of $12.5 \mathrm{~cm}$ falls with the estimated confidence intervals. 


\subsubsection{Confidence Interval around Mean Difference}

Probabilities of a random variable falling within some multiples of standard deviaion from the mean are known for any random variable that has a bell shaped distribution. Such intervals are known as confidence intervals around the mean. To construct such confidence intervals for mean difference of elevations, we need to check if the distribution of the mean differences is bell shaped. Histograms for various mean differences will be constructed and checked to see if they have a bell shaped distribution. If the distributions are observed to be bell-shaped, further quantitative analyses will be performed to verify that the distribution is normal. If the distribution of the mean differences is not found to be normal an alternative method to construct confidence intervals for random variables will be used. The alternative method is based on Chebyshev's Inequality, which is shown below [19]:

$$
P\left[\left(m_{X}-h \sigma_{X}\right) \leq X \leq\left(m_{X}+h \sigma_{X}\right)\right] \geq 1-\frac{1}{h^{2}} \quad, h>1
$$

where, $m_{X}$ and $\sigma_{X}$ are the mean and standard deviation of the random variable, $X$.

\subsubsection{Confidence Interval around RMSE}

To apply Chebyshev's Inequality to find confidence intervals around the RMSEs between pairs of elevations from remote source data and conventional elevations we need to first estimate the standard deviation of the RMSEs. The standard deviation of an RMSE can be estimated following Faber [20], who postulates that the relative uncertainty of RMSE is given by

$$
\frac{\sigma(R \hat{M S} E)}{R M S E}=\sqrt{\left(\frac{1}{2 n}\right)}
$$

where $n$ is the number of data points.

Confidence intervals for RMSE values that are below the ILC threshold of $12.5 \mathrm{~cm}$ will not need to be computed as these values satisfy the ILC standard. RMSE values that are too far above the limit of $12.5 \mathrm{~cm}$ will also not be tested as the confidence values for such RMSEs are not expected to contain $12.5 \mathrm{~cm}$, the threshold to satisfy the ILC standard. Only those RMSE values that are slightly over the limit of 12.5 will be tested.

\section{Results}

\subsection{Elevation Difference-Overall}

Table 2 shows the difference in elevations obtained from the conventional survey and each remote method DEM for all survey point locations using ArcMap. The conventional survey elevations were used as the "true" elevations.

Table 2. Statistics Related to Difference in Elevations for Different Data Sources.

\begin{tabular}{cccc}
\hline Data Source & Aerial Lidar & Mobile-Terrestrial Lidar & UAV Photogrammetric Capture \\
\hline RMSE $(\mathrm{cm})$ & 9.08 & 18.40 & 14.77 \\
Mean Difference (MD) $(\mathrm{cm})$ & -7.48 & -9.04 & -7.79 \\
Standard Deviation Sd $(\mathrm{cm})$ & 5.15 & 17.18 & 12.57 \\
Absolute MD (cm) & 7.53 & 9.55 & 9.29 \\
Relative Standard Deviation & $68.4 \%$ & $180 \%$ & $135 \%$ \\
\hline
\end{tabular}


The difference in elevation represented in Table 2 is the conventional survey elevation minus the elevation obtained from one of the three remote sources of data. Elevation differences for all locations irrespective of the ground slope or surface type were used. The mean difference was found to be negative for all three remote data sources, indicating that on average the remote data sources overestimated the ground elevation. The table shows that the aerial lidar elevations are closer to the surveyed elevations than those from the other two sources. The RMSE for mobile-terrestrial lidar was the highest in this analysis, with similar results for mean difference and standard deviation. The relative standard deviation values show that the mean differences had large variations. The relative standard deviation measure is comparable to the coefficient of variation statistic. The coefficient of variation statistic can be misleading when the mean of a random variable is a negative quantity, which is the case with the mean difference in Table 2. Hence, the absolute mean difference (MD) was computed and used to calculate the relative standard deviation.

\subsection{Elevation Difference-By Study Section}

Table 3 shows the results for the three road sections in which the verification survey data was collected. In all cases, the RMSE and standard deviation were high in Section 1. This was also true for mean difference except for the aerial lidar elevation differences. As in the aggregate case shown in Table 2, the precision of the measurements was higher in the case of aerial lidar relative to the other two sources. Section 2 for both mobile-terrestrial and UAV data had the greatest variability as indicated by the relative standard deviation measure.

Table 3. Statistics Related to Difference in Elevations for Three Sections.

\begin{tabular}{|c|c|c|c|c|c|c|c|c|c|}
\hline \multirow{2}{*}{$\begin{array}{c}\text { Data Source } \\
\text { Section }\end{array}$} & \multicolumn{3}{|c|}{ Aerial Lidar } & \multicolumn{3}{|c|}{ Mobile-Terrestrial Lidar } & \multicolumn{3}{|c|}{ UAV Photogrammetric Capture } \\
\hline & Section 1 & Section 2 & Section 3 & Section 1 & Section 2 & Section 3 & Section 1 & Section 2 & Section 3 \\
\hline $\operatorname{RMSE}(\mathrm{cm})$ & 9.5 & 9.1 & 8.4 & 23.5 & 11.1 & 16.3 & 17.4 & 13.6 & 12.9 \\
\hline Standard Deviation $(\mathrm{cm})$ & 6.1 & 5.2 & 3.7 & 20.5 & 9.8 & 13.3 & 13.6 & 12.8 & 9.5 \\
\hline Absolute MD (cm) & 7.3 & 7.6 & 6.7 & 12.5 & 5.6 & 8.3 & 12.0 & 7.0 & 8.1 \\
\hline Relative SD & $84 \%$ & $68 \%$ & $55 \%$ & $164 \%$ & $175 \%$ & $160 \%$ & $113 \%$ & $183 \%$ & $117 \%$ \\
\hline
\end{tabular}

\subsection{Elevation Difference-By Surface Type}

Table 4 presents the elevation differences for road- and non-road-surfaces. The RMSE for the road-surface points is much lower than that for the non-road-surface points. The RMSE for road-surface for all remote source data is quite acceptable within the standard accuracy limit stipulated by the Idaho Lidar Consortium (ILC). For points on the road-surface, mobile-terrestrial lidar gave the most accurate result among the three sources of data, while the aerial lidar had the highest RMSE $(5.4 \mathrm{~cm})$. The mean differences and standard deviations were also low for all remote data sources. It can be concluded that on road-surface areas, all these data types provide acceptable results.

Table 4. Statistics Related to Difference in Elevations for Road-Surface and Non-Road-Surface Survey Points.

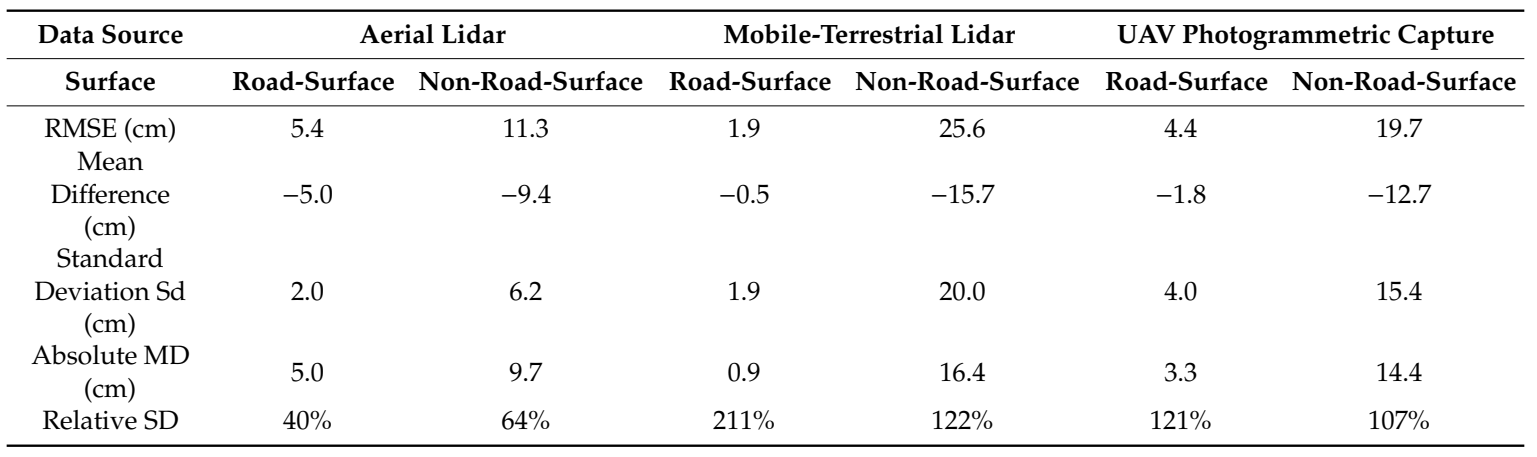


However, similar results were not observed for non-road-surface areas. The RMSE was high for all the remote data sources, with RMSEs higher than the $12.5 \mathrm{~cm}$ ILC standard for mobile-terrestrial and UAV sources. In terms of the ITD Highway Construction Specifications data for all remote sources met the verrtical tolerance values for natural ground. Aerial lidar achieved the closest result in terms of RMSE, mean difference, and standard deviation. This indicates that vertical accuracy of both the lidar and UAV photogrammetric data is significantly affected by non-road-surface returns for all of the alternatives. To summarize, it can be concluded that lidar and UAV photogrammetric data collected using survey control can achieve high accuracy for areas over a road surface with diminished accuracy for non-road surfaces.

The variability of mobile-terrestrial and UAV data appear to be high relative to aerial lidar data as measured by the relative SD statistic. This is because the relative SD measure takes larger values when the mean of the related random variable is smaller and is closer to zero.

\subsection{Elevation Difference-By Terrain Slope}

Table 5 shows results by slope of the ground using the previously described slope classification. From the table it can be concluded that the RMSE for aerial lidar was noticeably lower for moderate and steep slope areas when compared to either the mobile-terrestrial lidar or the UAV photogrammetric data. There were 922 survey points across the three road sections of the study area, and of these only 36 points were identified as level. More than half of the points were considered moderate, a total of 494 points, and 392 points were considered steep. The RMSE for all remote data types was lowest at points considered to be on level terrain. The RMSE for aerial lidar differences at points considered level was $4.91 \mathrm{~cm}$. The aerial lidar data had its highest RMSE in steep areas, at $11.00 \mathrm{~cm}$, which is below the ILC standard of $12.5 \mathrm{~cm}$. This, along with its RMSE of $7.48 \mathrm{~cm}$ for moderate areas, explains why the overall RMSE, all points considered, was lowest for the aerial lidar.

Table 5. Statistics Related to Difference in Elevations for Three Slope Areas.

\begin{tabular}{|c|c|c|c|c|c|c|c|c|c|}
\hline \multirow{2}{*}{$\begin{array}{c}\text { Data Source } \\
\text { Slope }\end{array}$} & \multicolumn{3}{|c|}{ Aerial Lidar } & \multicolumn{3}{|c|}{ Mobile-Terrestrial Lidar } & \multicolumn{3}{|c|}{ UAV Photogrammetric Capture } \\
\hline & Level & Mod. & Steep & Level & Mod. & Steep & Level & Mod. & Steep \\
\hline RMSE $(\mathrm{cm})$ & 4.91 & 7.48 & 11.00 & 4.36 & 10.99 & 24.57 & 3.95 & 9.92 & 18.94 \\
\hline $\begin{array}{c}\text { Mean } \\
\text { Difference }(\mathrm{cm})\end{array}$ & -4.65 & -6.54 & -8.92 & -0.80 & -3.42 & -15.29 & -1.90 & -3.68 & -12.48 \\
\hline $\begin{array}{c}\text { Standard } \\
\text { Deviation }(\mathrm{cm})\end{array}$ & 1.58 & 3.64 & 6.45 & 4.34 & 10.45 & 19.26 & 3.56 & 8.99 & 13.98 \\
\hline $\begin{array}{l}\text { Absolute MD } \\
(\mathrm{cm})\end{array}$ & 4.65 & 6.59 & 8.99 & 1.93 & 3.91 & 15.77 & 2.72 & 5.41 & 13.81 \\
\hline Relative SD & $34 \%$ & $55 \%$ & $72 \%$ & $225 \%$ & $267 \%$ & $122 \%$ & $131 \%$ & $166 \%$ & $101 \%$ \\
\hline
\end{tabular}

The variability in the measurements was also lower for aerial lidar data compared to the other two sources. It should be noted that the relative standard deviation of $225 \%$ for flat surface data collected by mobile-terrestrial lidar is misleading and is due to the low mean difference value for this case.

The RMSE for the mobile-terrestrial lidar was higher than aerial lidar for terrains with moderate or steep slopes. A total of 920 conventional survey points was available for comparison of the mobile-terrestrial lidar. Of these 920 points, only 39 points were on ground considered level. The highest number of points were considered moderate, a total of 458 . The remaining 423 points were considered steep. The mobile-terrestrial RMSE was $4.36 \mathrm{~cm}$ for level terrain, which was low compared to that for aerial lidar. The highest RMSE for mobile-terrestrial lidar was obtained in steep areas with an RMSE value of $24.57 \mathrm{~cm}$, while in moderate areas the RMSE was $10.99 \mathrm{~cm}$. The overall RMSE was high, due to the higher RMSE in the steep areas. Similar patterns are apparent in the mobile-terrestrial mean difference and standard deviation for each terrain type. All values were high for steep regions and low for level regions, following a pattern similar to the aerial lidar. 
The UAV photogrammetric data had a total of 918 usable survey points. Only 45 points were determined to be on level terrain. Among the three types of remote data, the UAV-based DEM had the highest number of survey points considered level and the RMSE was the lowest among all of them, with an RMSE for level terrain of $3.95 \mathrm{~cm}$. RMSE of the points considered to be on moderate terrain was $9.92 \mathrm{~cm}$. This RMSE was lower than that for the mobile-terrestrial lidar but higher than for aerial lidar, with 436 survey points considered on moderate terrain. A similar number of points were obtained for steep areas, 437 in total. The RMSE for steep areas was $18.94 \mathrm{~cm}$, which was the highest among the three types of terrain areas. Notably, the UAV data for steep areas was closer in accuracy than the mobile-terrestrial lidar. The mean difference and standard deviation for the UAV data appear to generally follow the same patterns as for the aerial lidar and mobile-terrestrial lidar. It is noted that the mean difference for all remote sources and slope types was within the vertical tolerance limit specified by ITD for natural ground. And except for areas with a steep slope for mobile-terrestrial and UAV data, all mean differences were with the vertical tolerance limit for graded surface.

\subsection{Summary of Elevation Differences}

In Figure 4, the RMSEs for the aerial lidar, mobile-terrestrial lidar and UAV photogrammetric data are shown for the different areas including the overall RMSE for these data sources. The figure illustrates that the aerial lidar elevations were generally the closest to the conventional survey elevations, although the RMSE for level areas was higher than the other two data types. However, this difference is relatively minimal. The UAV data had the second-closest elevational accuracy compared to the conventional survey, and mobile-terrestrial lidar had the least accurate RMSE, in large part due to steep areas and those away from the road surface. As noted previously, the verification survey locations were intentionally chosen as areas where the mobile-terrestrial lidar collection was likely to have difficulty with terrain away from the roadway.

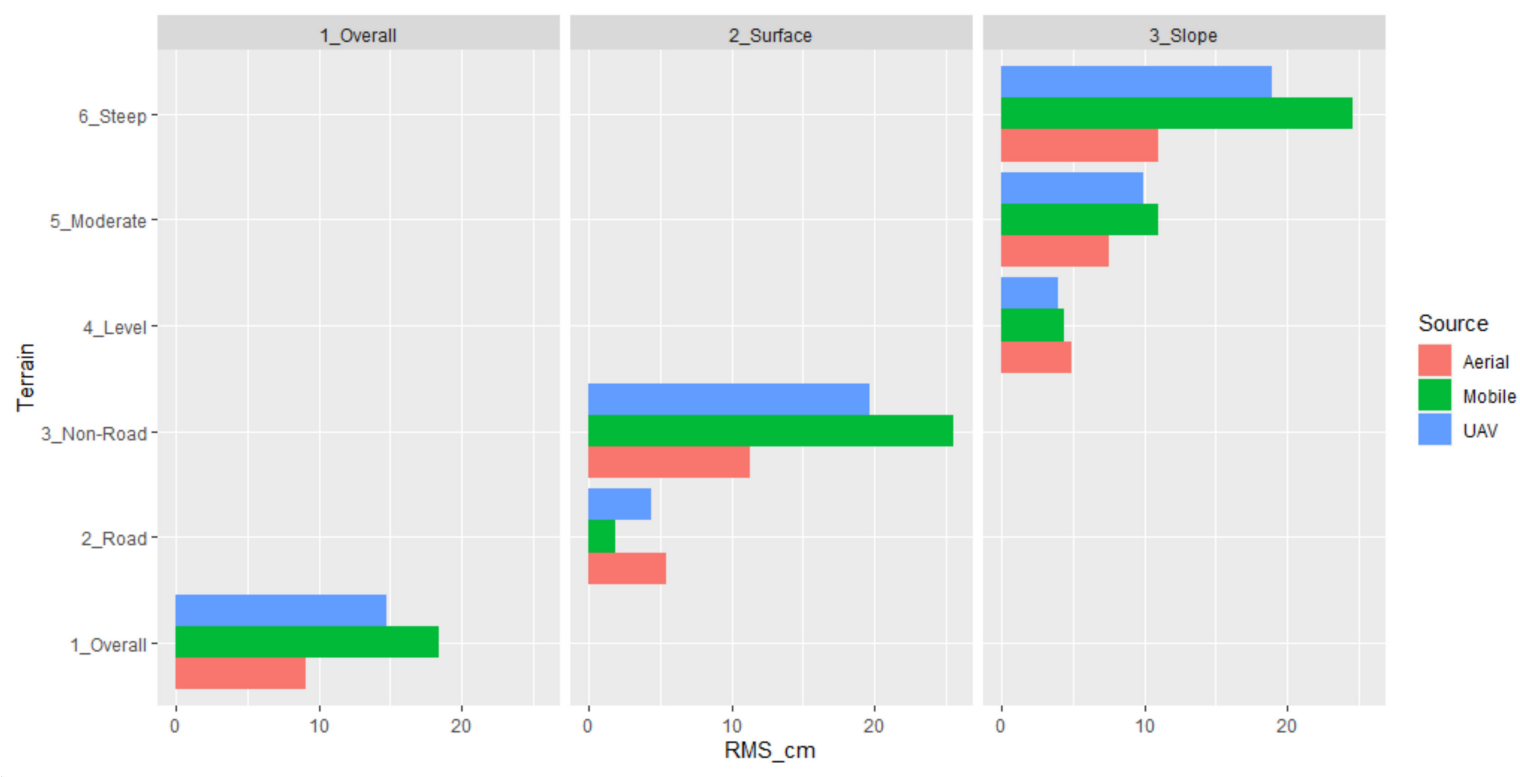

Figure 4. RMSE comparison by data type, location on/off road surface, and terrain slope.

\subsection{Statistical Analysis Results}

The two types of statistical analyses discussed earlier were performed on selected data sets presented in Tables 2-5. The first type is the estimation of confidence intervals around the mean difference for the various data sets shown in the tables. The second type of anlysis is to estimate confidence intervals around the calculated RMSE 


\subsubsection{Confidence Interval around Mean Difference}

To find a confidence interval around the mean elevation difference the first step needed is to determine whether the differences are normally distributed. To this end, histograms were constructed for all differences described in Tables 2-5. Figure 5 depicts the histogram for the difference between elevations computed using aerial lidar and conventional survey data. The mean for the differences, as noted in Table 2, is $-7.48 \mathrm{~cm}$. The figure shows that the histogram is not centered around this mean; the diagram is skewed to the left. There were also some outliers with high negative elevation difference

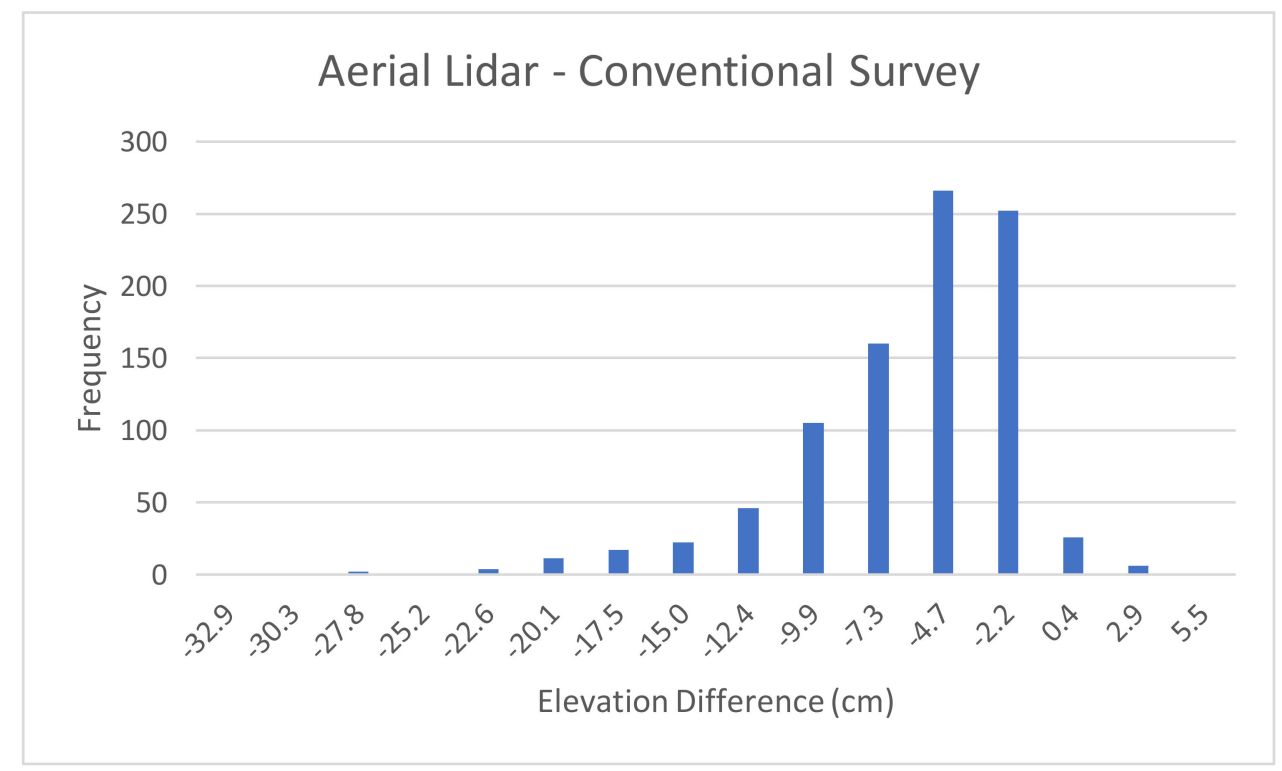

Figure 5. Elevation Difference Between Aerial Lidar and Conventional Survey.

Figure 6 depicts a similar histogram of differences between the mobile-lidar based elevations and the elevations estimated using conventional survey. The mean of the differences for this case is -9.04 . The histogram does not imply that the distribution of differences is centered around this mean value. The figure also shows that there some outliers in this data set.

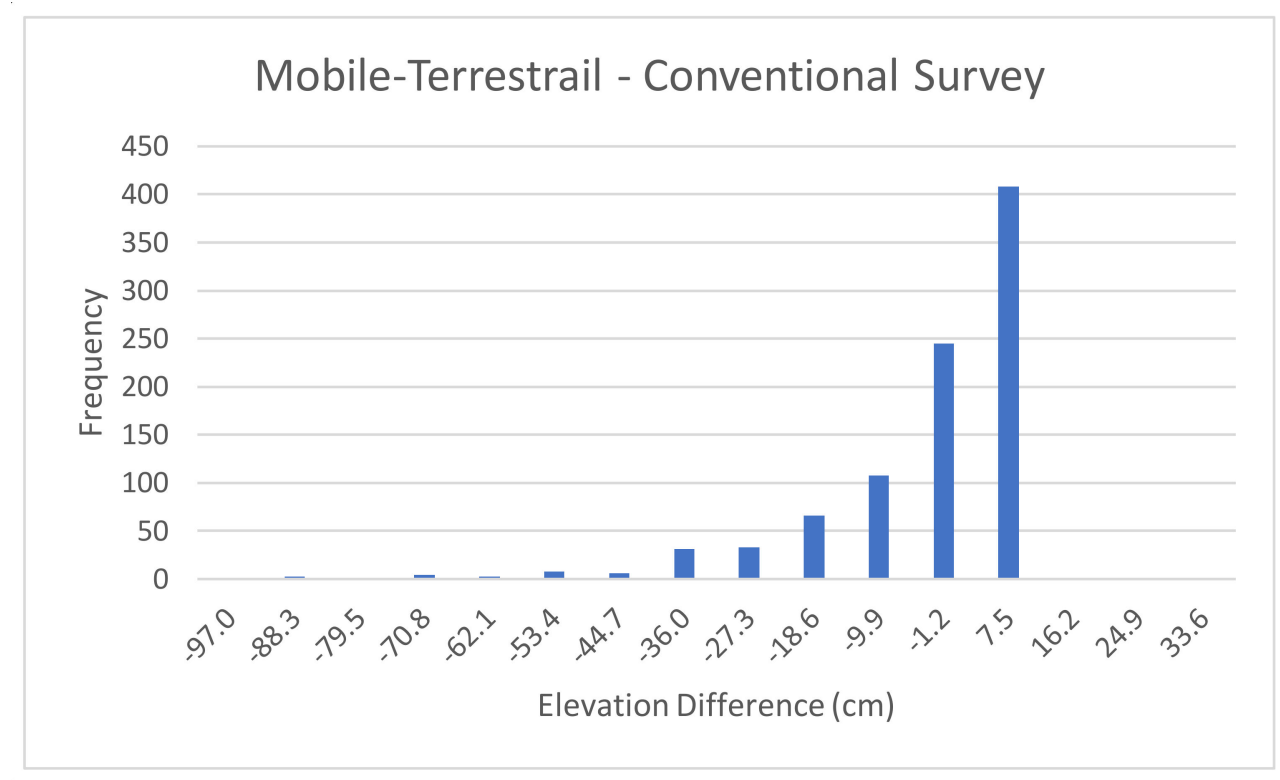

Figure 6. Elevation Difference Between Mobile-Terrestrial Lidar and Conventional Survey. 
Figure 7 depicts the histogram of differences between the UAV photogrammetric capture data based elevations and the elevations estimated using conventional survey. The mean of the differences for this case, as shown in Table 2, is $-7.79 \mathrm{~cm}$. The histogram shows that the elevation differences are not normally distributed around this mean. The figure also shows that there are some outliers in the data.

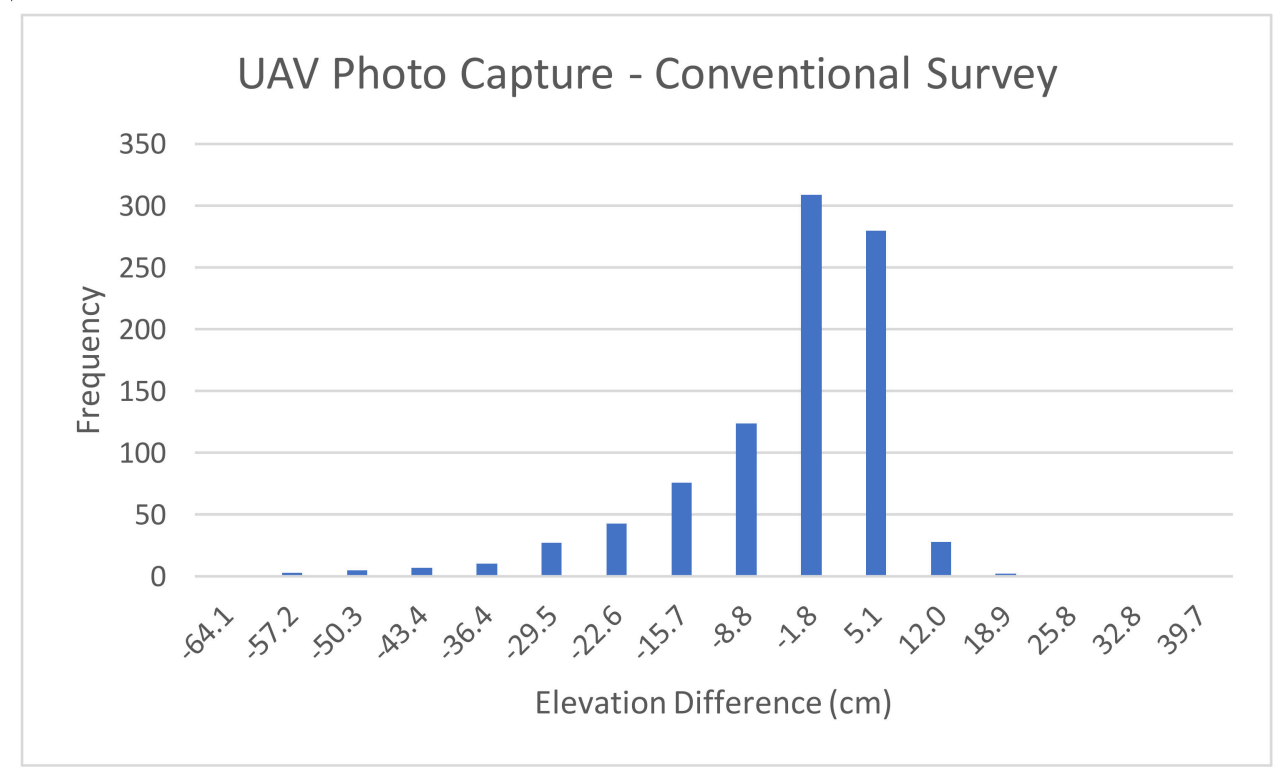

Figure 7. Elevation Difference Between UAV Photogrammetric Capture and Conventional Survey.

Since confidence intervals based on mulitples of the standard deviation around the mean cannot be used for any of the three cases above Chebyshev's Inequality was used for this purpose. Using Equation (1) the confidence intervals for the Mean Difference shown in Table 2 for the three remote sources with $h=2$ are: aerial: $(-17.78,2.82)$, mobile-terrestrial: $(-43.4,25.32)$, and UAV photogrammetric capture data: $(-32.93,17.39)$. The probability that the mean difference for each of the three remote sources will be in these intervals is at least $75 \%$. The intervals are wide and hence are not precise. But each of the intervals contains zero, a mean difference value that will be obtained when the measured elevations are, on the average, exactly equal to the assumed true values.

The Chebyshev's Inequality analysis was only done on the aggregate elevation data shown in Table 2. This analysis can be extended to all mean differences for the disaggregated data shown in Tables 3-5. The confidence intervals for some of these cases will be smaller because of lower values of mean difference as well as the associated standard deviation.

\subsubsection{Confidence Interval around RMSE}

Confidence intervals were computed using the formulation shown in Equation (2) for selected RMSE values shown in Tables 2-5. As mentioned in Section 2.4 above, only RMSE values that are slightly over the limit of $12.5 \mathrm{~cm}$ will be tested. The RMSE value which fits this criterion is the one for UAV in Table 2.

Using Equation (2), $\sigma_{R M S E}$ for the overall UAV data was estimated to be 0.34. The RMSEs for this case as shown in Table 2 is $14.77 \mathrm{~cm}$. Using $h=3$ in the formula for Chebyshev's Inequality (Equation (1)), the $89 \%$ confidence intervals for the RMSE is $(13.74,15.81)$. Since even the lower limit of this interval exceeds the ILC threshold of $12.5 \mathrm{~cm}$, the overall UAV data does not meet the ILC standard. The confidence interval for the overall mobile-terrestrial RMSE was not computed as the RMSE for this source is even higher than the one for UAV. The lower limit for the $89 \%$ confidence limit for the mobile-terrestrial lidar RMSE is also expected to exceed the ILC threshold. Hence, the accuracy of the mobile-terrestrial lidar data, when considered as a whole, does not meet the ILC standard. 


\subsection{Cost Comparison}

For the cost comparsion, the twelve miles of US-30 between mileposts 413 and 425 where the mobile-terrestrial lidar was collected in Bear Lake County are considered. Table 6 lists the costs of collecting and processing each data type for a roadway project of this magnitude:

Table 6. Cost comparison of each data source type.

\begin{tabular}{cccccc}
\hline Data Source & $\begin{array}{c}\text { Conventional } \\
\text { Survey }\end{array}$ & $\begin{array}{c}\text { Aerial Lidar, } \\
\text { Districtwide } \\
\text { Collection }\end{array}$ & $\begin{array}{c}\text { Aerial Lidar, } \\
\text { Comparable } \\
\text { Single-Project }\end{array}$ & $\begin{array}{c}\text { Mobile-Terrestrial } \\
\text { Lidar }\end{array}$ & $\begin{array}{c}\text { UAV } \\
\text { Photogrammetric } \\
\text { Capture (Estimated) }\end{array}$ \\
\hline Cost $(19.31 \mathrm{~km})$ & $\$ 145,256.60$ & $\$ 8145.25$ & $\$ 123,992.58$ & $\$ 88,646.40$ & $\$ 25,000.00$ \\
Cost $($ per km) & $\$ 7521.52$ & $\$ 421.77$ & $\$ 6420.45$ & $\$ 4590.19$ & $\$ 1294.52$ \\
\hline
\end{tabular}

The conventional survey cost refers to the use of a Total Station to record optical data observations. This methodology was used in the conventional survey verification cross-sections, used as the basis for all accuracy comparisons in this study. ITD paid Dioptra Geomatics $\$ 6877.68$ for the approximate $915 \mathrm{~m}$ of cross-sections of highway surveyed for project A019(382) to produce the three verification cross-section areas. The above cost was derived as follows:

$$
19.31 \mathrm{~km}=19.31 \mathrm{~km} / 0.915 \mathrm{~km}=21.12 \text { cross-sections } \times \$ 6877.68=\$ 145,256.60
$$

The planning-grade aerial lidar used in this study is part of a districtwide collection effort, including 1152 linear $\mathrm{km}$ of roadway. Economies of scale are important to note in determining the cost of such an extensive project. The total cost of the project, including ground survey control by AeroGraphics' survey crew, as well as the collection of aerial imagery by Aero-Graphics, Inc., orthorectified imagery, DEM raster surfaces, and other data processing, was $\$ 486,000$, from which the $19.31 \mathrm{~km}$ and per $\mathrm{km}$ figures were derived.

However, if a consultant collected aerial lidar on a more limited basis at design-grade (as the mobile-terrestrial lidar was), rather than districtwide at planning-grade, the cost would likely be significantly more. This may in large part be due to the necessity of mobilizing the collection aircraft. To approximate this cost, a comparable aerial lidar collection effort such as that for ITD project keys 14,002 and 13106, flown in 2014, could be used for comparison. The invoiced amount of the combined lidar collection for these projects was $\$ 123,992.58$.

It should be noted that the comparison here is not perfectly analogous to the US-30 project area, as it is for a different part of the highway system, multiple stretches of highway, and includes numerous side roads, which may make for a more complex flight pattern. However, the total highway distance with these two roads is similar to the US-30 study area and should make for a reasonable comparison with the US-30 study area data costs.

The total invoice for the mobile-terrestrial lidar collected by R.E.Y. Engineers, including control, supplemental survey data, and conventional verification data by Dioptra Geomatics, was $\$ 88,646.40$. This collection spanned $19.31 \mathrm{~km}$ (12 miles) between MP 413-425 on US-30. Finally, because the UAV photogrammetric data was collected and processed in-house by ITD, the cost in the table is an approximate estimate of the cost as provided by consultants. Figure 8 depicts the cost comparison pictorially. 


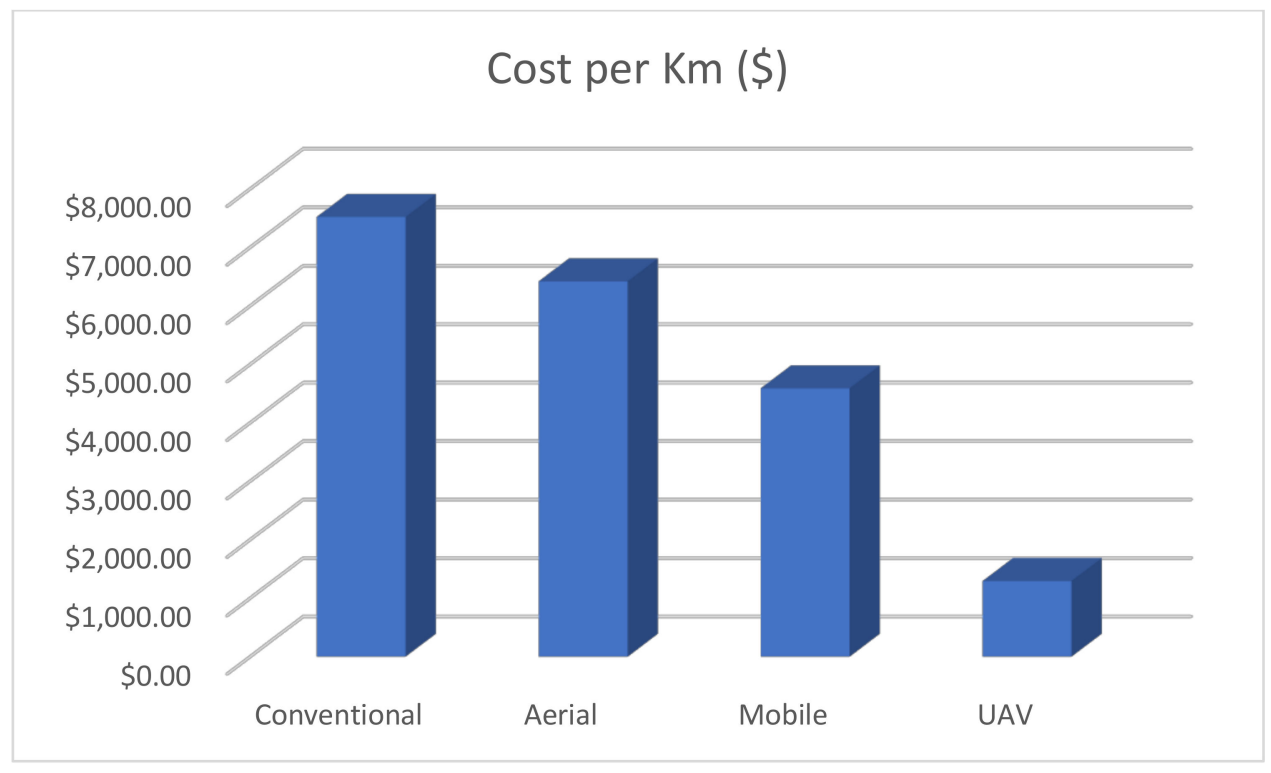

Figure 8. Per Km Cost for Different Data Collection Methods.

\section{Discussion}

Table 7 below presents how the data shown in Tables $2-5$ compare with the ITD specification for vertical tolerance and the ILC vertical accuracy standard. An "yes" in a cell for any row with "RMSE" in the first column indicates that the source data for the cell satisfies the ILC standard. The word in a cell for any row with "Mean Difference" in the first column denotes the surface type for which the vertical tolerance shown in Table 1 is met. For example, if the word in a cell is "Graded" for any "Mean Difference" row, it means that the vertical tolerance for the remote data source satisfies ITD's highway construction specification for machine graded and compacted surface.

In terms of the RMSE standard stipulated by ILC, aerial lidar data was found to be satisfactory in all cases: overall, by study sections, by surface type, and by terrain slope. Mobile-terrestrial and UAV photogrammetric capture data on the other hand did not meet this specification when the data for the entire study area is considered. When examined in a more disaggregated fashion they met the standard in some cases. For example, mobile-terrestrial data met the ILC standard in Section 2, on road surface, and on level and moderate slopes. Likewise, UAV photogrammetric capture data met the ILC standard on road surface and on level and moderate slopes.

In terms of ITD's vertical tolerance limits for highway construction, all three remote data sources were within the tolerance limit for machine graded and compacted surface when viewed at an aggregate level covering the entire study area. This is a significant finding. This implies that terrain models created using remotely collected data can be used for new road designs as well as reconstruction and rehabilitation of existing roads.

At more disaggregated levels, when ground surface type and slope of the terrain are considered, the accuracy of each data type degraded at higher steepness and off-pavement. Spaete et al. have noted that vegetation and slope areas have a statistically significant impact on the accuracy of lidar-derived DEMs [21]. Our study has indicated that the aerial lidar provided the most accurate terrain information in these areas. Considering the vantage point of the aerial lidar with its capability of multiple returns, this makes sense. The mobile-terrestrial lidar is understandably limited by its ground vantage point, especially in areas with steep slopes. 
Table 7. Conformance with Available Standards.

\begin{tabular}{|c|c|c|c|c|c|c|c|c|c|}
\hline Data Source & \multicolumn{3}{|c|}{ Aerial Lidar } & \multicolumn{3}{|c|}{ Mobile-Terrestrial Lidar } & \multicolumn{3}{|c|}{ UAV Photogrammetric Capture } \\
\hline RMSE $(\mathrm{cm})$ & \multicolumn{3}{|c|}{ Yes } & \multicolumn{3}{|c|}{ No } & \multicolumn{3}{|c|}{ No } \\
\hline Mean Difference (cm) & \multicolumn{3}{|c|}{ Graded } & \multicolumn{3}{|c|}{ Graded } & \multicolumn{3}{|c|}{ Graded } \\
\hline Section & Section 1 & Section 2 & Section 3 & Section 1 & Section 2 & Section 3 & Section 1 & Section 2 & Section 3 \\
\hline RMSE $(\mathrm{cm})$ & Yes & Yes & Yes & No & Yes & No & No & No & No \\
\hline Mean Difference (cm) & Graded & Graded & Graded & Natural & Graded & Graded & Natural & Graded & Graded \\
\hline Surface & \multicolumn{2}{|c|}{ Road-Surface } & Non-Road-Surface & \multicolumn{2}{|c|}{ Road-Surface } & Non-Road-Surface & \multicolumn{2}{|c|}{ Road-Surface } & Non-Road-Surface \\
\hline RMSE (cm) & \multicolumn{2}{|c|}{ Yes } & Yes & \multicolumn{2}{|c|}{ Yes } & No & \multicolumn{2}{|c|}{ Yes } & No \\
\hline Mean Difference (cm) & \multicolumn{2}{|c|}{ Graded } & Natural & \multicolumn{2}{|c|}{ Surfaced } & Natural & \multicolumn{2}{|c|}{ Surfaced } & Natural \\
\hline Slope & Level & Mod. & Steep & Level & Mod. & Steep & Level & Mod. & Steep \\
\hline RMSE $(\mathrm{cm})$ & Yes & Yes & Yes & Yes & Yes & No & Yes & Yes & No \\
\hline Mean Difference (cm) & Graded & Graded & Graded & Surfaced & Graded & Natural & Surfaced & Graded & Natural \\
\hline
\end{tabular}


The three conventional verfication areas were deliberately selected to be areas likely difficult for the mobile-terrestrial to achieve accuracy away from the pavement. The UAV photogrammetric capture method, while having an aerial vantage point, is limited by being based on photographic images. This means foliage is likely to have a major impact on its accuracy. Another possible consideration is the processing method each remote. las dataset received. The aerial lidar received some manual processing, while the mobile-terrestrial and UAV data both relied on an automated ground-classifying process in ArcMap. Manual processing of the mobile-terrestrial lidar and UAV photogrammetric data may improve the accuracy of these data types in off-road and steeper areas.

It is also important to point out that the difference in implications from the two set of standards, the ILC standards for RMSE and the vertical tolerance limits from ITD's Highway Construction Specifications. According to the latter the vertical accuracy from all three remote sources satisfy the requirements for natural ground for all types of surfaces and for all degrees of slopes. That is not the case when using the ILC standard for RMSE. If the ILC standard is used, then only aerial lidar will be suitable for all types of surfaces and all degrees of slope. Mobile-terrestrial and UAV photogrammetric capture data do not satisfy the ILC standard for RMSE for non-road surfaces and grounds with a steep slope.

The vertical accuracy levels we were able to achieve in our research were not the same as those claimed by the vendors who collected the aerial lidar and mobile-terrestrial lidar data. As mentioned in Section 2.2 above the aerial lidar data vendor have claimed an RMSE of $3.14 \mathrm{~cm}$ for open and non-vegetated areas. The lowest RMSE we were able to achieve with aerial lidar data was $4.91 \mathrm{~cm}$ for level areas as shown in Table 5. Similarly, the mobile-terrestrial vendor claims an RMSE value of $0.732 \mathrm{~cm}$ for pavement plus edge of pavement and $4.3 \mathrm{~cm}$ for "ground" points; these are points not on pavement or edge of pavement. These RMSE of error values are lower than what we were able to achieve. As can be seen in Table 4, $1.9 \mathrm{~cm}$ was the lowest RMSE value we obtained with mobile-terrestrial data; this was for points on a road surface. Further research is needed to explain these differences in accuracy levels. However, it can be stated here that highway agencies are advised to conduct random quality assessment of data received from outside vendors.

Regarding the UAV data, the RMSEs of error between control point elevations and point cloud derived elevations were $17.1 \mathrm{~cm}, 1.9 \mathrm{~cm}$, and $15.8 \mathrm{~cm}$ respectively for the three study sections, as stated in Section 2.2 earlier. RMSE values obtained in our study for the three sections were $17.4 \mathrm{~cm}, 13.6 \mathrm{~cm}$, and $12.9 \mathrm{~cm}$, as shown in Table 3. Except for Section 2 the two sets of RMSE values are comparable. It is to be noted that the UAV data was collected in-house by ITD unlike the two other remote sources of data.

In closing, a stepwise recommendation to highway agencies about using vendor-supplied, remote source data for highway design is provided below:

1. Require a detailed explanation of vertical accuracies from vendors. The vendor report should include details about the software used in the processing of the point cloud data.

2. Divide your project area into at least thirty, approximately equal regions.

3. Establish a verification point in each of the regions and measure the elevation of the point using a conventional survey method, such as a Total Station or RTK-GPS.

4. Estimate the elevation of each of the points using a DEM based on the remote source data obtained from the vendor.

5. Compute the RMSE and the average difference in elevation between the two sets of elevations.

6. If the values obtained in Step 5 above meet applicable standards for your jurisdiction, the DEM derived from the remote source data may be used for highway design.

7. If the test in Step 6 is not successful, do not accept the vendor supplied remote source data. 


\section{Conclusions}

The findings reported here indicate that the source of data used in highway design may be expanded to include remote sources. For reconstruction and rehabilitation projects where terrain models of road or other paved surfaces are required, mobile-terrestrial or UAV sources may be more appropriate due to cost and convenience. For larger projects where data from undeveloped land will be required, aerial lidar appear to be more appropriate due to higher levels of accuracy. It is noted however that the results presented in this paper are based on data collected by a unique set of equipment. Implications from changing the equipment for data collection have not been explored. But Further studies are needed to confirm the findings reported here. But based on the results presented here including the accuracy standards reported by the vendors, we recommend that highway agencies should begin to consider making increasing use of remote data sources in highway design.

An additional recommendation for future research is the use of standard highway design software to process the point cloud data obtained from remote data collection. This study used ArcMap; there should be some future studies that use highway design software to process the point cloud data. Highway designers are not as familiar with GIS software as they are with highway design software. Promising results based on highway design software are expected to lead to increased acceptance of remotely collected among highway design professionals.

Author Contributions: Conceptualization, M.K. and M.H.; Data curation, M.K. and M.H.; Formal analysis, M.K.; Methodology, M.K.; Resources, N.S., R.J. and J.W.; Software, M.K. and M.H.; Writing-Original draft, M.K., M.H., N.S., R.J. and J.W.; Writing-Review \& editing, M.K., N.S. and R.J. All authors have read and agreed to the published version of the manuscript.

Funding: This research received no external funding.

Acknowledgments: The authors would like to thank the Idaho Transportation Department for providing the data for use in this study.

Conflicts of Interest: The authors declare no conflict of interest.

\section{References}

1. Veneziano, D.; Souleyrette, R.; Hallmark, S. Evaluation of Lidar for Highway Planning, Location, and Design. In Proceedings of the Integrated Remote Sensing at the Global, Regional and Local Scale. ISPRS Comission I. Mid-Term Symposium in Conjunction with Pecora, Denver, CO, USA, 10-15 November 2002. Available online: https://www.researchgate.net/publication/238620013 (accessed on 15 April 2019).

2. Idaho Transportation Department. Standard Specifications for Highway Construction, Section 600; Idaho Transportation Department: Boise, ID, USA, 2018; pp. 489-490.

3. Idaho Lidar Consortium. Idaho Lidar Standards, Ver 1.0; Idaho Lidar Consortium: Boise, ID, USA. Available online: https://www.idhaolidar.org/blog/2015/04/10/3421/ (accessed on 23 May 2019).

4. Chang, J.; Findley, D.; Cunnigham, C.; Tsai, M. Considerations for Effective Lidar Deployment by Transportation Agencies. Transp. Res. Rec. J. Transp. Res. Board 2014, 2440, 1-8. [CrossRef]

5. Pourali, S.; Arrowsmith, C.; Chrisman, N.; Matkan, A. Vertical Accuracy Assessment of Lidar Ground Points Using Minimum Distance Approach. CEUR Workshop Proc. 2014, 1142, 86-96.

6. Hodgson, M.; Bresnahan, P. Accuracy of Airborne Lidar-Derived Elevation: Empirical Assessment and Error Budget. Photogramm. Eng. Remote Sens. 2004, 70, 331-340. [CrossRef]

7. Cui, Z. A Generalized Adaptive Mathematical Morphological Filter for Lidar Data. Ph.D. Thesis, Florida International University, Miami, FL, USA, 2013.

8. Goodwin, N.R.; Coops, N.C.; Culvenor, D.S. Assessment of Forest Structure with Airborne Lidar and the Effects of Platform Altitude. Remote Sens. Environ. 2006, 103, 140-152. [CrossRef]

9. Smith, A.M.S.; Falkowski, M.J.; Hudak, A.T.; Evans, J.S.; Robinson, A.P.; Steele, C.M. A Cross-Comparison of Field, Spectral, and Lidar Estimates of Forest Canopy Cover. Can. J. Remote Sens. 2009, 35, 447-459. [CrossRef]

10. Bowen, Z.H.; Waltermire, R.G. Evaluation of Light Detection and Ranging (LiDAR) for Measuring River Corridor Topography. J. Am. Water Resour. Assoc. 2002, 38, 33-41. [CrossRef] 
11. Asner, G.P. Tropical Forest Carbon Assessment: Integrating Satellite and Airborne Mapping Approaches. Environ. Res. Lett. 2009, 4, 034009. [CrossRef]

12. Shrestha, R.L.; Carter, W.E.; Lee, M.; Finer, P.; Sartori, M. Airborne Laser Swath Mapping: Accuracy Assessment for Surveying and Mapping Applications. J. Am. Congr. Surv. Mapp. 1999, 59, 83-94.

13. Heidemann, H.K. Lidar Base Specification, Version 1.3. In U.S. Geological Survey Techniques and Methods, Book 11; US Geological Survey: Reston, VA, USA, 2018; p. 101.

14. Tinkham, W.T.; Huang, H.; Smith, A.M.S.; Shrestha, R.; Falkowski, M.J.; Hudak, A.T.; Link, T.E.; Glenn, N.F.; Marks, D.G. A Comparison of Two Open Source Lidar Surface Classification Algorithms. Remote Sens. 2011, 3, 638-649. [CrossRef]

15. Gatziolis, D.; Fried, J.S.; Monleon, V.S. Challenges to Estimating Tree Height via Lidar in Closed-Canopy Forests: A Parable from Western Oregon. For. Sci. 2010, 56, 139-155.

16. Aero-Graphics. Technical Project Report: D5 Aerial Photography and Lidar; Aero-Graphics: Salt Lake City, UT, USA, 2017.

17. R.E.Y. Engineers. Mobile Scan Survey Report: ITD Project A019(382)-Key No. 19382; R.E.Y. Engineers: Folsom, CA, USA, 2016.

18. American Association of State Highway and Transportation Officials. A Policy on Geometric Design of Highways and Streets, 6th ed.; American Association of State Highway and Transportation Officials: Washington, DC, USA, 2011.

19. Benjamin, J.R.; Cornell, C.A. Probability, Statistics, and Decision for Civil Engineers; McGraw-Hill Book Company: New York, NY, USA, 1970.

20. Faber, N.M. Estimating the Uncertainty in Estimates of Root Mean Square Error of Prediction: Application to Determining the Size of an Adequate Test Set in Multivariate Calibration. Chemom. Intell. Lab. Syst. 1999, 49, 79-89. [CrossRef]

21. Spaete, L.P.; Glenn, N.F.; Derryberry, D.R.; Sankey, T.T.; Mitchell, J.J.; Hardegree, S.P. Vegetation and Slope Effects on Accuracy of a Lidar-Derived DEM in the Sagebrush Steppe. Remote Sens. Lett. 2011, 2, 317-326. [CrossRef]

(C) 2020 by the authors. Licensee MDPI, Basel, Switzerland. This article is an open access article distributed under the terms and conditions of the Creative Commons Attribution (CC BY) license (http://creativecommons.org/licenses/by/4.0/). 